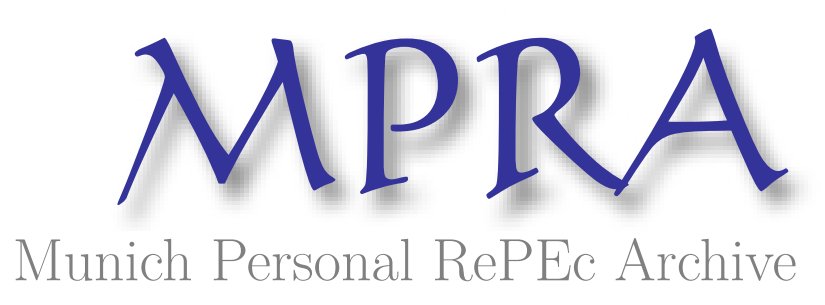

\title{
Urban Public Pension, Replacement Rates and Population Growth Rate in China
}

Yang, Zaigui

October 2009

Online at https://mpra.ub.uni-muenchen.de/18846/

MPRA Paper No. 18846, posted 26 Nov 2009 01:55 UTC 


\title{
Urban Public Pension, Replacement Rates and Population Growth Rate in China
}

\author{
Zaigui Yang \\ School of Insurance, Central University of Finance and Economics, Beijing, 100081, PR China \\ Tel: +86-10-6228 8628 \\ Fax: +86-10-6228 9350 \\ E-mail address: yangzaigui@hotmail.com (Z. Yang)
}

\begin{abstract}
This paper uses an overlapping generations model to investigate the urban public pension in China. It examines the effects of the replacement rates and population growth rate on the capital-labor ratio, pension benefits, consumption and utility, and finds the optimal replacement rate. It is shown that raising the individual account benefit replacement rate only increases the individual account benefits. Raising the social pool benefit replacement rate induces the increase in the social pool benefits and retirement-period consumption, while the decrease in the capital-labor ratio, individual account benefits, working-period consumption and utility. The fall in the population growth rate leads to the increase in the capital-labor ratio, social pool benefits, individual account benefits, working-period consumption and utility, while the decrease in the retirement-period consumption. The optimal social pool benefit replacement rate depends on the individual discount factor, social discount factor, capital share of income and population growth rate, and it decreases in the case of fallen population growth rate. It will do more good than harm to raise the individual account benefit replacement rate, reduce the social pool benefit replacement rate and strictly implement China's population policy.
\end{abstract}

Keywords: Urban public pension; Replacement rate; Population growth rate

JEL Classification: H55, D91

Subject Category: IE25

Insurance Branch Category: IB80 


\section{Introduction}

The publication of "The Chinese State Council Decision on Improving the Basic Pension System for Enterprise Employees" in December 2005 implies a new round of reform of the urban public pension system in China. The government discloses the target replacement rate of pension benefits via the People's Daily as follows: "The target replacement rate before the reform was $58.5 \%$, where the social pool benefit replacement rate was $20 \%$ and the individual account benefit replacement rate $38.5 \%$. The target replacement rate after the reform is $59.2 \%$, where the social pool benefit replacement rate is $35 \%$ and the individual account benefit replacement rate $24.2 \%$." ${ }^{1}$ The government has increased the pension benefits in recent years, and denoted to continue increasing. Hence, it is valuable to answer the following questions: what level should be the optimal replacement rate, what is the criterion to determine the optimal replacement rate, what are the determinant elements, and how should the optimal replacement rate be calculated?

Some of the literature on public pension with overlapping generations (OLG) model study pay-as-you-go (PAYG) pension system (e.g., Pecchenino and Pollard, 2002; Groezen et al., 2003). Several studies analyze fully funded pension system (e.g., Abel, 1987). Some investigate both PAYG and fully funded pension systems (e.g., Altig and Davis, 1993; Zhang et al., 2001). This paper will explore China's partially funded public pension system combining social pool and individual accounts. Samuelson (1975) studies the optimum social security in a life-cycle growth model. He adjusts the capital-labor ratio to the modified golden rule level to maximize the social welfare by controlling the social security taxes. The approach to find the optimal social security taxes is to equate the rate of interest to the growth rate of economy in a decentralized economy. Blanchard and Fischer (1989) elaborate the principle of social optimum, which is the Pareto Optimum. A social planner maximizes the social welfare by rationally allocating the social resources.

In the above literature, pensions are financed only by wage taxes. However, in most of the countries that have public pension systems, the governments levy pension taxes on each employee's wage and on each enterprise's payroll using a proportional taxation

\footnotetext{
${ }^{1}$ See Bai (2005) for details.
} 
schedule. Thus in this model, as real life, the government levies pension taxes on each worker's wage and on each firm's payroll; and the pension taxes are proportional taxes.

The population growth rate in China is also taken into account in this model since it has been falling in the last three decades. This is mainly because of China's special population policy. In general, the government requires a couple to have not more than one child. In some special cases, e.g., both wife and husband are one child in their respective families before they get married, a couple of peasants with no child but a daughter, a couple from the minority nationalities with population below one million persons, and so on, the couples are eligible to have two or more children. There are some ways for rural residents to become urban residents. For example, graduated college students get jobs in urban area; military officers transfer to civilian works in urban area; urbanization makes corresponding rural residents become urban residents; and so on.

Employing an OLG model within general equilibrium framework, this paper investigates China's urban public pension system. It examines the effects of the individual account benefit replacement rate, social pool benefit replacement rate and population growth rate on the capital-labor ratio, social pool benefits, individual account benefits, working-period consumption, retirement-period consumption and utility. This paper also seeks the optimal replacement rate. Under the specializations of logarithmic utility function and Cobb-Douglas production function, we use the data such as urban population, capital share of income and the like in China to simulate the effects of the exogenous variables on the endogenous variables and that of the population growth rate on the optimal social pool benefit replacement rate.

The rest of this paper is organized as follows: Section 2 presents the model in decentralized economy. Section 3 examines the effects of the exogenous variables. Section 4 simulates the effects in the last section. Section 5 derives the optimal social pool benefit replacement rate and simulates the effect of the population growth rate on it. Section 6 gives the conclusions.

\section{The model}

A closed economy is composed of numerous individuals and firms and a government. 
The generation born at the beginning of period $t$ is called generation $t$. The population grows at the rate of $n=N_{t} / N_{t-1}-1$, where $N_{t}$ is the population size of generation $t$.

\subsection{Individuals}

Individuals live for two periods: working period and retirement period. In the working period, each individual earns wage by supplying inelastically one unit of labor, makes pension contributions, consumes part of the incomes and saves the rest. In the retirement period, she/he consumes the savings with accrued interest, individual account benefits and social pool benefits.

Each individual derives utility from her/his working-period consumption $c_{1 t}$ and retirement-period consumption $c_{2 t+1}$. The utility is described by an additively separable logarithmic function. Each individual maximizes her/his utility by choosing lifetime consumption and savings, thus solves the following maximization problem:

$$
\begin{aligned}
& \max _{\left\{c_{1 t}, c_{2 t+1}, s_{t}\right\}} U_{t}=\ln c_{1 t}+\theta \ln c_{2 t+1}, \\
& \text { s.t. } \quad c_{1 t}=(1-\tau) w_{t}-s_{t}, \\
& c_{2 t+1}=\left(1+r_{t+1}\right) s_{t}+B_{t+1}+P_{t+1},
\end{aligned}
$$

where $\theta \in(0,1)$ denotes the individual discount factor, $\tau$ the individual contribution rate, $w_{t}$ the wage, $s_{t}$ the savings, $r_{t+1}$ the interest rate, $B_{t+1}$ the individual account benefits, and $P_{t+1}$ the social pool benefits.

The first-order condition for the utility maximization is

$$
-c_{2 t+1}+\theta\left(1+r_{t+1}\right) c_{1 t}=0 .
$$

This familiar expression implies that the utility loss from reducing one unit of working-period consumption is equal to the utility gain from increasing $\left(1+r_{t+1}\right)$ units of retirement-period consumption discounted by $\theta$.

\subsection{Firms}

Firms produce homogeneous commodity in competitive markets. The production is 
described by Cobb-Douglas function $Y_{t}=A K_{t}^{\alpha} N_{t}^{1-\alpha}$ or $y_{t}=A k_{t}^{\alpha}$, where $Y_{t}$ is the output in period $t, K_{t}$ the capital stock, $\alpha \in(0,1)$ the capital share of income, $A$ the productivity, $k_{t}=K_{t} / N_{t}$ the capital-labor ratio, and $y_{t}$ the output-labor ratio.

Firms make pension contributions at the rate of $\eta \in(0,1)$ on their payroll. According to the product distribution, one can get $A K_{t}^{\alpha} N_{t}^{1-\alpha}=r_{t} K_{t}+(1+\eta) w_{t} N_{t}$. Firms act competitively, renting capital to the point where the marginal product of capital is equal to its rental rate, and hiring labor to the point where the marginal product of labor is equal to $(1+\eta) w_{t}$ :

$$
\begin{gathered}
r_{t}=\alpha A k_{t}^{\alpha-1}, \\
w_{t}=\frac{(1-\alpha) A k_{t}^{\alpha}}{1+\eta} .
\end{gathered}
$$

\subsection{The government}

The social pool fund is paid to the retirees in the current period as PAYG pension benefits: $P_{t} N_{t-1}=\eta w_{t} N_{t}$. Using the definition of social pool benefit replacement rate $\xi$ gives

$$
P_{t}=\xi w_{t}=(1+n) \eta w_{t},
$$

thus

$$
\eta=\frac{\xi}{1+n} .
$$

The accumulation in the individual account is used to pay the individual when she retires in the next period as funded pension benefits. Using the definition of individual account benefit replacement rate $\mu$ gives

$$
B_{t+1}=\mu w_{t+1}=\left(1+r_{t+1}\right) \tau w_{t},
$$

thus

$$
\tau=\frac{\mu}{1+r_{t+1}} \cdot \frac{w_{t+1}}{w_{t}} .
$$




\subsection{Dynamic Equilibrium}

The savings and the individual pension contributions in period $t$ generate the capital stock in period $t+1$ (See Blanchard and Fischer, 1989 or Barro and Sala-I-Martin, 2004):

$$
s_{t}+\tau w_{t}=(1+n) k_{t+1} \text {. }
$$

A competitive equilibrium for the economy is a sequence as $\left\{c_{1 t}, c_{2 t+1}, s_{t}, w_{t}, r_{t+1}, B_{t+1}, P_{t+1}, k_{t+1}\right\}_{t=0}^{\infty}$ that satisfies equations (1)-(11) for all $t$, given the initial condition $k_{0}$ and the values of parameters $\mu$ and $\xi$.

Substituting equations (2), (3) and (5)-(11) into (4) gives a dynamic equilibrium system described by the following difference equation:

$$
-\left(k_{t+1}+\alpha A k_{t+1}^{\alpha}\right)-\frac{\xi(1-\alpha)}{1+n+\xi} A k_{t+1}^{\alpha}+\theta\left(1+\alpha A k_{t+1}^{\alpha-1}\right) \cdot\left(\frac{1-\alpha}{1+n+\xi} A k_{t}^{\alpha}-k_{t+1}\right)=0 .
$$

Assume that there exists unique, stable and nonoscillatory equilibrium. In order to find the stability condition, we linearize Dynamic System (12) around the steady state $(k)$. Some manipulation gives

$$
a\left(k_{t+1}-k\right)+e\left(k_{t}-k\right)=0
$$

where

$$
\begin{gathered}
a=-\left(1+\alpha^{2} A k^{\alpha-1}\right)-\frac{\xi}{1+n+\xi}(1-\alpha) \alpha A k^{\alpha-1}-\theta(1-\alpha) \alpha A k^{\alpha-2}\left(\frac{1-\alpha}{1+n+\xi} A k^{\alpha}-k\right)-\theta\left(1+\alpha A k^{\alpha-1}\right), \\
e=\theta\left(1+\alpha A k^{\alpha-1}\right) \frac{1-\alpha}{1+n+\xi} \alpha A k^{\alpha-1}>0 .
\end{gathered}
$$

The assumption that the equilibrium is unique, stable and nonoscillatory is equivalent to $0<\frac{k_{t+1}-k}{k_{t}-k}=-\frac{e}{a}<1$. Therefore, the stability condition is

$$
a+e<0 .
$$

\section{Comparative Statics}


Totally differentiating equation (12) around the steady state gives

$$
(a+e) d k+i d \xi+j d n=0
$$

where

$$
\begin{gathered}
i=-\frac{(1-\alpha) A k^{\alpha}}{(1+n+\xi)^{2}}\left[(1+n)+\theta\left(1+\alpha A k^{\alpha-1}\right)\right]<0, \\
j=\frac{(1-\alpha) A k^{\alpha}}{(1+n+\xi)^{2}}\left[\xi-\theta\left(1+\alpha A k^{\alpha-1}\right)\right]<0 \text { if } \xi<\theta\left(1+\alpha A k^{\alpha-1}\right) .
\end{gathered}
$$

In general, the condition of $\xi<\theta\left(1+\alpha A k^{\alpha-1}\right)$ can be satisfied because $\xi$ is usually less than $50 \%$ and $\theta$ more than $50 \%$.

\subsection{Effects of individual benefit replacement rate}

Using equation (14) gives

$$
\frac{\partial k}{\partial \mu}=0
$$

In the steady state, the social pool benefits, individual account benefits, working-period consumption, retirement-period consumption and utility become

$$
\begin{aligned}
& P=\xi \frac{1+n}{1+n+\xi}(1-\alpha) A k^{\alpha}, \\
& B=\mu \frac{1+n}{1+n+\xi}(1-\alpha) A k^{\alpha}, \\
& c_{1}=(1+n)\left(\frac{1}{1+n+\xi}(1-\alpha) A k^{\alpha}-k\right), \\
& c_{2}=(1+n)\left(k+\alpha A k^{\alpha}+\frac{\xi}{1+n+\xi}(1-\alpha) A k^{\alpha}\right), \\
& U=\ln c_{1}+\theta \ln c_{2} .
\end{aligned}
$$

Obviously, raising the individual account benefit replacement rate has no effect on the capital-labor ratio, social pool benefits, working-period consumption, 
retirement-period consumption and utility, but increases the individual account benefits.

From equation (16), one can get that raising the individual account benefit replacement rate increases the individual account benefits. In the steady state, a rise in the individual account benefit replacement rate implies the increase in the individual contribution rate, further the rise in the individual pension contributions. Because the individual savings are crowded out by one for one when the individual pension contributions (the mandatory savings) increases, the individual account benefit replacement rate has no effect on the capital-labor ratio, furthermore, no effect on the social pool benefits by virtue of equation (15). Similarly, it has no effect on the working-period consumption, retirement-period consumption and utility.

\subsection{Effects of social pool benefit replacement rate}

Using equation (14) gives

$$
\frac{\partial k}{\partial \xi}=-\frac{i}{a+e}<0
$$

Differentiating $P, B, c_{1}, \quad c_{2}$ and $U$ with respect to $\xi$ gives

$$
\frac{\partial P}{\partial \xi}=-\frac{(1+n)^{2}(1-\alpha) A k^{\alpha}}{(a+e)(1+n+\xi)^{2}}\left\{\begin{array}{l}
\left(1+\alpha^{2} A k^{\alpha-1}\right)+\theta \alpha(1-\alpha) A k^{\alpha-2}\left(\frac{1-\alpha}{1+n+\xi} A k^{\alpha}-k\right) \\
+\theta\left(1+\alpha A k^{\alpha-1}\right)\left(1-\frac{1-\alpha}{1+n} \alpha A k^{\alpha-1}\right)
\end{array}\right\}>0,
$$

where $c_{1}=(1+n)\left(\frac{1-\alpha}{1+n+\xi} A k^{\alpha}-k\right)>0$ and $(1+n)>(1-\alpha) r$ have been used.

$$
\begin{gathered}
\frac{\partial B}{\partial \xi}=\frac{\mu(1+n)(1-\alpha) A k^{\alpha}}{(a+e)(1+n+\xi)^{2}}\left\{\begin{array}{l}
\left(1+\alpha A k^{\alpha-1}\right)+\theta \alpha(1-\alpha) A k^{\alpha-2}\left(\frac{1-\alpha}{1+n+\xi} A k^{\alpha}-k\right) \\
+\theta\left(1+\alpha A k^{\alpha-1}\right)
\end{array}\right\}<0, \\
\frac{\partial c_{1}}{\partial \xi}=\frac{(1+n)(1-\alpha) A k^{\alpha}}{(a+e)(1+n+\xi)^{2}}\left\{\left(\alpha A k^{\alpha-1}-n\right)+\theta \alpha(1-\alpha) A k^{\alpha-2}\left(\frac{1-\alpha}{1+n+\xi} A k^{\alpha}-k\right)\right\}<0 \text { if }
\end{gathered}
$$




$$
\begin{gathered}
r>n, \\
\frac{\partial c_{2}}{\partial \xi}=\frac{(1+n)^{2}(1-\alpha) A k^{\alpha}}{(a+e)(1+n+\xi)^{2}}\left\{\left(\alpha A k^{\alpha-1}-n\right) \theta \frac{1+\alpha A k^{\alpha-1}}{1+n}-\theta \alpha(1-\alpha) A k^{\alpha-2}\left(\frac{1-\alpha}{1+n+\xi} A k^{\alpha}-k\right)\right\}>0 \\
\text { if } r<n, \\
\frac{\partial U}{\partial \xi}=\left(\alpha A k^{\alpha-1}-n\right) \frac{\theta(1+n)(1-\alpha) A k^{\alpha}}{c_{2}(a+e)(1+n+\xi)^{2}}\left\{(1+\theta)\left(1+\alpha A k^{\alpha-1}\right)+\theta \alpha(1-\alpha) A k^{\alpha-2}\left(\frac{1-\alpha}{1+n+\xi} A k^{\alpha}-k\right)\right\} \\
\frac{\partial U}{\partial \xi}<0 \text { if } r>n, \frac{\partial U}{\partial \xi}>0 \text { if } r<n .
\end{gathered}
$$

Raising the social pool benefit replacement rate decreases the capital-labor ratio and individual account benefits, increases the social pool benefits, decreases the working-period consumption if the interest rate is higher than the population growth rate, increases the retirement-period consumption if the interest rate is lower than the population growth rate, decreases the utility if the interest rate is higher than the population growth rate and vice versa.

A rise in the social pool benefit replacement rate increases the social pool benefits, thus the savings for consumption in retirement period fall, further the capital-labor ratio decreases. Raising the social pool benefit replacement rate directly increases the social pool benefits, while decreases the wage, which indirectly decreases the social pool benefits. The former dominates the later and increases the social pool benefits. The decrease in the wage induces the fall in the individual account benefits. The working-period consumption decreases because the effect of the fall in the wage dominates that of capital-labor ratio if the interest rate is higher than the population growth rate. The retirement-period consumption increases because the effect of the rises in the social pool benefits and interest rate dominates that of the fall in the capital-labor ratio if the interest rate is lower than the population growth rate. The utility decreases since the working-period consumption falls when the interest rate is higher than the population growth rate, and increases since the retirement-period consumption rises when the interest rate is lower than the population growth rate. 


\subsection{Effects of population growth rate}

Using equation (14) gives

$$
\frac{\partial k}{\partial n}=-\frac{j}{a+e}<0 \text { if } \xi<\theta\left(1+\alpha A k^{\alpha-1}\right)
$$

A fall in the population growth rate increases the capital-labor ratio because of the centralized effect in capital-labor ratio. Differentiating $P$ and $B$ with respect to $n$ gives

$$
\left.\begin{array}{l}
\frac{\partial P}{\partial n}=-\frac{\xi(1-\alpha) A k^{\alpha}}{(a+e)(1+n+\xi)^{2}}\left\{\begin{array}{l}
\xi \theta \alpha(1-\alpha) A k^{\alpha-2}\left(\frac{1-\alpha}{1+n+\xi} A k^{\alpha}-k\right) \\
+\left(1+\alpha A k^{\alpha-1}\right)\left[(1+\theta) \xi-\theta(1-\alpha) \alpha A k^{\alpha-1}\right]
\end{array}\right\}, \\
\frac{\partial B}{\partial n}=-\frac{\mu(1-\alpha) A k^{\alpha}}{(a+e)(1+n+\xi)^{2}}\left\{\begin{array}{l}
\xi \theta \alpha(1-\alpha) A k^{\alpha-2}\left(\frac{1-\alpha}{1+n+\xi} A k^{\alpha}-k\right) \\
+\left(1+\alpha A k^{\alpha-1}\right)\left[(1+\theta) \xi-\theta(1-\alpha) \alpha A k^{\alpha-1}\right.
\end{array}\right]
\end{array}\right\} .
$$

The signs of the two partial derivatives cannot be judged because a fall in the population growth rate has more effects on $P$ and $B$, whose directions and magnitudes are complicated. It can be shown that the partial derivatives of $c_{1}, c_{2}$ and $U$ with respect to $n$ are more complex. The effects of the population growth rate on the five endogenous variables depend on the values of the related parameters. Hence, we estimate the parameters at first and then check the effects by simulating.

\section{Simulations}

\subsection{Estimation of parameter values}

According to the disclosure of the People's Daily, the target replacement rate of pension benefits has been adjusted from January 1, 2006. The social pool benefit replacement rate $\xi$ has been raised from $20 \%$ to $35 \%$, and the individual account benefit replacement rate $\mu$ reduced from $38.5 \%$ to $24.2 \%$.

Assume that the individual discount factor per year is 0.98 , which is similar to that found by Auerbach and Kotlikoff (1987) and used by Pecchenino and Utendorf (1999). 
Hence, the individual discount factor per period (26 years ${ }^{2}$ ) is $\theta=0.98^{26}$.

There are several calibers for population statistics in China. Since the public pension system in urban area is different from that in rural area, and only the former is studied in this paper, so the caliber of "Urban Population" is selected. The population growth rate 3 during the period $1978-2004$ is computed at $n \approx 2.148$ according to the "Population and Its Composition” in China Statistical Yearbook.

The capital share of income, $\alpha$, is usually to be estimated as 0.3 in developed countries (e.g., Zhang et al., 2001; Pecchenino and Pollard, 2002; Barro and Sala-I-Martin, 2004). The labor in China is comparatively cheaper, thus the labor share of income is lower, while the capital share of income is higher than that in developed countries. Hence, we assume that $\alpha$ in China could be 0.35 .

Since what we want to see here is how the endogenous variables change relatively with the exogenous variables, the constant $A$ can be normalized as 1 . The benchmark values of the above parameters are shown in Table 1.

Table 1 Parameter benchmark values

\begin{tabular}{cccccc}
\hline$\theta$ & $\alpha$ & $A$ & $\xi$ & $\mu$ & $n$ \\
\hline $0.98^{26}$ & 0.35 & 1 & $35 \%$ & $24.2 \%$ & 2.148 \\
\hline
\end{tabular}

\subsection{Simulation on social pool benefit replacement rate}

At first, let the social pool benefit replacement rate be $20 \%$. Substituting the above parameter benchmark values into equation (12) in the steady state and calculating repeatedly until the equation holds, one can get the capital-labor ratio, $k \approx 0.0161$. Substituting the estimated $k$ and the related parameter benchmark values into equations (15)-(19) gives the social pool benefits, individual account benefits, working-period consumption, retirement-period consumption and utility. Then, let the social pool benefit replacement rate be $28 \%$ (we take this rate between $20 \%$ and $35 \%$ ) and $35 \%$, respectively.

\footnotetext{
2 There are two reasons to choose a period length of 26 years in this model. One is that the length is usually in the interval of 25-30 years in the literature on OLG model. The other is the structure of the data in China.

${ }^{3}$ This is equivalent to the average population growth rate per year, $(1+2.148)^{1 / 26}-1 \approx 4.51 \%$. As the literature, we also use the value per period in the text.
} 
Repeating the above procedure yields the result shown in Table 2.

Table 2 Effects of social pool benefit replacement rate

\begin{tabular}{cccc}
\hline$\xi$ & $20 \%$ & $28 \%$ & $35 \%$ \\
\hline$k$ & 0.0161 & 0.0150 & 0.0142 \\
$P$ & 0.0288 & 0.0384 & 0.0461 \\
$B$ & 0.0348 & 0.0332 & 0.0319 \\
$c_{1}$ & 0.0934 & 0.0900 & 0.0873 \\
$c_{2}$ & 0.33876 & 0.33898 & 0.33902 \\
$U$ & -3.0112 & -3.0473 & -3.0787 \\
\hline
\end{tabular}

Raising the social pool benefit replacement rate decreases the capital-labor ratio, increases the social pool benefits, decreases the individual account benefits and working-period consumption, increases the retirement-period consumption, and decreases the utility. The simulation justifies the counterpart in the comparative statics.

\subsection{Simulation on population growth rate}

Since the current term, 2005-2015, is more concerned, we look into the population growth rates during the periods ( 26 years per period) including the current term, such as period 1984-2010 and period 1989-2015. It is necessary to predict the urban population in each year from 2007 to 2015 . The sample is the urban population in each year from 1978 to 2006. Using the TREND function in Microsoft Excel gives the result shown in Appendix A. The $R^{2}$ value is 0.9725 , which implies a very good fit. Computing the population growth rates yields that the rate during period 1984-2010 is 1.500 , and that during period 1989-2015 is 1.272 . Simulating with the estimated population growth rates and the benchmark parameter values gives the result shown in Table 3.

Table 3 Effects of population growth rate

\begin{tabular}{cccc}
\hline$n$ & 2.148 & 1.500 & 1.272 \\
\hline$k$ & 0.0142 & 0.0189 & 0.0212 \\
$P$ & 0.0461 & 0.0498 & 0.0512 \\
$B$ & 0.0319 & 0.0344 & 0.0354 \\
$c_{1}$ & 0.0873 & 0.0949 & 0.0980 \\
$c_{2}$ & 0.3390 & 0.3152 & 0.3060 \\
$U$ & -3.0787 & -3.0376 & -3.0228 \\
\hline
\end{tabular}


The fall in the population growth rate increases the capital-labor ratio, social pool benefits, individual account benefits, working-period consumption, decreases the retirement-period consumption, and increases the utility.

\section{The Pareto Optimum}

Since the social pool benefit replacement rate, one of the policy variables, has effect on the capital-labor ratio, it is possible to find the optimal social pool benefit replacement rate to maximize the social welfare. The social welfare function is defined as the sum of the lifetime utilities of all current and future generations ${ }^{4}$ :

$$
W=\theta \ln c_{20}+\sum_{i=0}^{\infty} \rho^{i}\left(\ln c_{1 i}+\theta \ln c_{2 i+1}\right)
$$

where $\rho \in(0,1)$ is the social discount factor, which reflects the preference of the social planner. The resource constraint is

$$
k_{i}+A k_{i}^{\alpha}=(1+n) k_{i+1}+c_{1 i}+c_{2 i} /(1+n)
$$

The initial condition is that $k_{0}$ is given.

The social planner maximizes the social welfare subject to the resource constraint and initial condition. Appendix B gives the first-order conditions for the social welfare maximization problem:

$$
\begin{gathered}
\theta(1+n) c_{1}^{*}=\rho c_{2}^{*} \\
1+\alpha A\left(k^{*}\right)^{\alpha-1}=\frac{1+n}{\rho}, \text { or } k^{*}=\left(\frac{1+n-\rho}{\rho \alpha A}\right)^{\frac{1}{\alpha-1}}
\end{gathered}
$$

where the superscript * denotes the optimal steady state values of variables. The capital-labor ratio satisfying equation (23) is at the modified golden rule level, which means that the social welfare reaches the maximum.

In order to maximize the social welfare of the decentralized economy in the steady state, we control the policy variable to adjust the capital-labor ratio of the decentralized economy in the steady state to the modified golden rule level, namely, $k=k^{*}$.

\footnotetext{
${ }^{4}$ Blanchard and Fischer (1989) and Groezen et al. (2003) also use an analogous social welfare function.
} 
Substituting equation (23) into equation (12) and arranging gives

$$
\xi^{*}=\frac{1+n}{\rho} \cdot \frac{\theta(1-\alpha)(1+n-\rho)-\rho \alpha(1+\theta)(1+n)}{\alpha(1+\theta)(1+n)+(1-\alpha)(1+n-\rho)} .
$$

The optimal social pool benefit replacement rate depends on the population growth rate $n$, individual discount factor $\theta$, social discount factor $\rho$, and capital share of income $\alpha$.

To examine the effect of the population growth rate on the optimal social pool benefit replacement rate, we differentiate $\xi^{*}$ with respective to $n$. It is shown that the effect is dependent on the related parameter values, which also can be checked by simulating.

It is necessary to estimate the social discount factor at first, which indicates how much the government weights different generations in its social welfare calculations. Hence, it should be estimated according to the government's regulations. Based on the disclosure of the People' Daily, the target replacement rate of social pool benefits is $35 \%$, which is the optimal social pool benefit replacement rate adopted by the government. Substituting the related parameter benchmark values in Table 1 into equation (24) and calculating repeatedly until the equation holds, one can get that $\rho \approx 0.47913$.

Substituting the fallen population growth rate, 1.500, and the benchmark values of $\theta$ and $\alpha$ and the estimated $\rho$ into equation (24) gives the optimal social pool benefit replacement rate, $21.14 \%$. When the population growth rate falls to 1.272 , simulating analogously gives the result shown in Table 4.

Table 4 Optimal social pool benefit replacement rates under different population growth rates

\begin{tabular}{cccc}
\hline$n$ & 2.148 & 1.500 & 1.272 \\
\hline$\xi^{*}$ & $35.00 \%$ & $21.14 \%$ & $16.16 \%$ \\
\hline
\end{tabular}

The optimal social pool benefit replacement rate falls with the population growth rate. The fall in the population growth rate increases the capital-labor ratio, further raises the wage. When the effect of these increases dominates that of the fall in the population growth rate, the incomes in retirement-period will rise. The social welfare maximization needs to retain the optimal retirement-period consumption. Hence, the optimal social pool 
benefit replacement rate has to be adjusted to fall with the population growth rate.

\section{Conclusions}

Employing the OLG model with general equilibrium, this paper investigates the urban public pension in China. We examine the effects of the individual account benefit replacement rate, social pool benefit replacement rate and population growth rate on the capital-labor ratio, social pool benefits, individual account benefits, working-period consumption, retirement-period consumption and utility. By controlling the policy variable to adjust the capital-labor ratio to the modified golden rule, we find the optimal social pool benefit replacement rate. Adopting logarithmic utility function and Cobb-Douglas production function, we use the data in China such as the urban population, capital share of income, target replacement rates, etc., to simulate the effects of the exogenous variables on the endogenous variables and that of the population growth rate on the optimal social pool benefit replacement rate.

The main results are shown in Table 5. Raising the individual account benefit replacement rate has no effect on the capital-labor ratio, social pool benefits, consumption and utility, but increases the individual account benefits. Raising the social pool benefit replacement rate increases the social pool benefits and retirement-period consumption, while decreases the capital-labor ratio, individual account benefits, working-period consumption and utility. The fall in the population growth rate increases the capital-labor ratio, social pool benefits, individual account benefits, working-period consumption and utility, while decreases the retirement-period consumption.

The optimal social pool benefit replacement rate depends on the population growth rate, individual discount factor, social discount factor and capital share of income. It decreases when the population growth rate has fallen.

Table 5 Effects of replacement rates and population growth rate

\begin{tabular}{ccccccc}
\hline & $k$ & $P$ & $B$ & $c_{1}$ & $c_{2}$ & $U$ \\
\hline$\mu \uparrow$ & 0 & 0 & + & 0 & 0 & 0 \\
$\xi \uparrow$ & - & + & - & - & + & - \\
$n \downarrow$ & + & + & + & + & - & + \\
\hline
\end{tabular}


The above results include the following policy implications: ( i ) In order to decrease the capital-labor ratio to restrain the over-fast growth of capital assets investment in China in most years of the last two decades, it is necessary to raise the social pool benefit replacement rate or properly relax the population policy. (ii) To increase the social pool benefits, it is necessary to raise the social pool benefit replacement rate or strictly implement the population policy. (iii) To increase the individual account benefits, it is necessary to raise the individual account benefit replacement rate, or reduce the social pool benefit replacement rate or strictly implement the population policy. (iv) To increase the consumption of the workers, it is necessary to reduce the social pool benefit replacement rate or strictly implement the population policy. (v) To increase the consumption of the retirees, it is necessary to raise the social pool benefit replacement rate or properly relax the population policy. (vi) To raise the utility level, it is necessary to reduce the social pool benefit replacement rate or strictly implement the population policy.

The following two results strengthen the implication of reducing properly the social pool benefit replacement rate. Firstly, raising the social pool benefit replacement rate will increase the social pool benefits and retirement-period consumption, whereas decrease the utility. If we define the median aim of raising the social pool benefit replacement rate as to increase the social pool benefits and retirement-period consumption, and the ultimate aim to increase the utility, then raising the social pool benefit replacement rate can realize the median aim but runs counter to the ultimate aim. Secondly, the optimal social pool benefit replacement rate should decrease rationally when the population growth rate has fallen. This is derived from the social welfare maximization. In a word, it will do more good than harm to raise the individual account benefit replacement rate, reduce the social pool benefit replacement rate and strictly implement the population policy.

\section{Appendix A}

Predicted urban population in each year from 2007 to $2015 \quad$ (10000 persons)

\begin{tabular}{cccccccccc}
\hline Year & 2007 & 2008 & 2009 & 2010 & 2011 & 2012 & 2013 & 2014 & 2015 \\
\hline Population & 55794 & 57208 & 58621 & 60035 & 61448 & 62862 & 64276 & 65689 & 67103 \\
\hline
\end{tabular}




\section{Appendix B}

The Lagrange function for the social welfare maximization problem is

$$
\begin{aligned}
L & =\cdots \\
& +\rho^{t-1}\left(\ln c_{1 t-1}+\theta \ln c_{2 t}\right)+\lambda_{t-1}\left[k_{t-1}+A k_{t-1}^{\alpha}-(1+n) k_{t}-c_{1 t-1}-\frac{c_{2 t-1}}{1+n}\right] \\
& +\rho^{t}\left(\ln c_{1 t}+\theta \ln c_{2 t+1}\right)+\lambda_{t}\left[k_{t}+A k_{t}^{\alpha}-(1+n) k_{t+1}-c_{1 t}-\frac{c_{2 t}}{1+n}\right] \\
& +\rho^{t+1}\left(\ln c_{1 t+1}+\theta \ln c_{2 t+2}\right)+\lambda_{t+1}\left[k_{t+1}+A k_{t+1}^{\alpha}-(1+n) k_{t+2}-c_{1 t+1}-\frac{c_{2 t+1}}{1+n}\right] \\
& +\cdots
\end{aligned}
$$

where $\lambda_{t}$ is the Lagrange multiplier for the resource constraint in period $t$. Let the partial derivatives of $L$ with respect to $c_{1 t}, c_{2 t}$ and $k_{t+1}$ be zero:

$$
\begin{aligned}
& \rho^{t} / c_{1 t}-\lambda_{t}=0, \\
& \rho^{t-1} \theta / c_{2 t}-\lambda_{t} /(1+n)=0, \\
& -\lambda_{t}(1+n)+\lambda_{t+1}\left(1+\alpha A k_{t+1}^{\alpha-1}\right)=0 .
\end{aligned}
$$

Arranging equations (A1)-(A3) at the optimal steady state $\left(k^{*}, c_{1}^{*}, c_{2}^{*}\right)$ yields equations (22) and (23).

\section{Acknowledgement}

Financial support from the Social Science Foundation of the Ministry of Education of China (No. 06JA630079) is gratefully acknowledged. The author is grateful to the anonymous referees and the editors for helpful comments and suggestions. Any remaining omissions or errors are the author's responsibility.

\section{References}

Abel, A.B., 1987. Aggregate savings in the presence of private and social insurance. In: R. Dornbusch et.al. (Eds.), Macroeconomics and Finance: Essays in Honor of Franco Modigliani. Cambridge: MIT Press.

Altig, D. and S.J. Davis, 1993. Borrowing constraints and two-sided altruism with an 
application to social security. Journal of Economic Dynamics and Control 17, 476-494.

Auerbach, A.J. and L.J. Kotlikoff, 1987. Dynamic Fiscal Policy. Cambridge: Cambridge University Press.

Bai, T., 2005-12-15. What is the new in the new public pension policy. The People's Daily. (Bai Tianliang: Yanglao xinjucuo xin zainaer)

Barro, R. J. and X. Sala-I-Martin, 2004. Economic Growth. Cambridge: MIT Press.

Blanchard, O.J. and S. Fischer, 1989. Lectures on Macroeconomics. London: MIT Press.

Groezen, B., T. Leers and L. Meijdam, 2003. Social security and endogenous fertility: pensions and child allowances as siamese twins. Journal of Public Economics 87, 233-251.

Pecchenino, R., and K. Utendorf, 1999. Social security, social welfare and the aging population. Journal of Population Economics 12, 607-623.

Pecchenino, R. and P. Pollard, 2002. Dependent children and aged parents: funding education and social security in an aging economy. Journal of Macroeconomics 24, 145-169

Samuelson, P.A., 1975. Optimum social security in a life-cycle growth model. International Economic Review 16, 539-544.

Zhang, J., J. Zhang and R. Lee, 2001. Mortality decline and long-run economic growth. Journal of Public Economics 80, 485-507. 